\title{
HPTLC analysis of berberine in stem extracts of Fibraurea darshani
}

Sheema Dharmapal P. ${ }^{*}$, Bindu T.K.1, P.S. Udayan ${ }^{1}$ and K.K. Elyas ${ }^{2}$

${ }^{1}$ PG Department of Botany and Research Centre, Sree Krishna College, Guruvayur, Ariyannur P.O., Thrissur Dst, Kerala, India. .680102.

2Department of Biotechnology, University of Calicut, Calicut University P.O., Malappuram, Kerala, India. 673635.

Received: 1/8/2018; Accepted: 1/27/2018

\begin{abstract}
The present study is a first report on the phytochemical analysis of the plant Fibraurea darshani which is endemic to Western Ghats. The plant is a woody dioecious climber belonging to the family Menispermaceae. Preliminary phytochemical screening of methanolic extracts of the stem of $F$. darshani revealed the presence of secondary metabolites like alkaloids, carbohydrates, anthraquiones, terpenoids, flavonoids, phenolics, sterols etc. A simple and reproducible high performance thin layer chromatography was developed to evaluate the presence of berberine in methanol extract of stem of F. darshani. This method involves separation of compounds by HPTLC on pre-coated silica gel $60 \mathrm{~F} 254$ plates with a solvent system of Chloroform: Ethyl acetate: Methanol: Formic acid (4:5:4:0.3) and scanned using densitometric scanner in UV reflectance photo mode at 254 and $366 \mathrm{~nm}$. The $\mathrm{R}_{\mathrm{f}}$ values (0.97) for berberine in the plant sample and the reference standard were found comparable under UV light at 366nm. The HPTLC method developed was simple, accurate and specific.
\end{abstract}

Keywords: Berberine, Fibraurea darshani, HPTLC, Methanolic extract, Phytochemical screening

\section{Introduction}

The genus Fibraurea Lour. belonging to the family Menispermaceae consists of two species namely Fibraurea recisa Pierre. and Fibraurea tinctoria Lour. and is mostly restricted to East and South East Asia including Andaman and Nicobar islands (Forman, 1985; Kubitzki et al., 1993, Pramanik, 1993; Mabberely, 2005). Fibraurea species have been used in traditional medicines of Thailand and other Asian countries like China (Perry and Metzger, 1980). The stem of F. recisa is an effective antifungal herb, and its major active component was reported to be alkaloidal water-soluble berberines (Rao et al., 2009). Berberine $\left(B_{1}\right)$ is an isoquinoline alkaloid reported to have antidiabetic, antipyretic, antimalarial, antiprotozoal (Leishmania), antimicrobial and antitumour activities (Patani, 2002). Berberine has been tested and used successfully in experimental and human diabetes and found to lower elevated glucose level as effectively as metformin (Yin et al., 2008). The alkaloids pseudocolumbamine, palmatrubine, magnoflorine and dehydrocorydalmine were isolated and identified by their spectral data from the root and stem bark of $F$. tinctoria. The extracts from the stem of F. tinctoria showed antioxidant activity on DPPH radical and also exhibited cytotoxic activity against brine shrimp and human cancer cell line MCF-7 (Keawpradub et al., 2005).

Fibraurea darshani Udayan \& Ravikumar is a relatively new species reported from Karnataka and Kerala states of South India. F. darshani is a woody dioecious climber found in semi ever green forests.

\section{${ }^{*}$ Corresponding Author:}

Sheema Dharmapal,

Research Scholar,

Sree Krishna College, Guruvayur,

Ariyannur, Thrissur District, Kerala, India.

E-mail: sheemamohandaas@gmail.com
Flowering and fruiting is observed in January-April months. F. darshani is an endangered plant endemic to Western Ghats (Udayan et al., 2007).

The popularity of herbal drugs in the global health care has increased due to its remarkable efficacy in the treatment of various ailments. Some 120 chemicals extracted in pure form from about 90 species of higher plants are used in medicines throughout the world; an extremely wide range of plant species being used medicinally at a local level (Dar and Farooq, 1997). Specific guiding principles has been developed by the World Health Organization to support the associated countries to instigate nationalized policies on plant based drugs and to study their prospective safety, efficacy and quality, as a prerequisite for global harmonization (Calixto, 2000). The plant extracts are subjected to preliminary phytochemical analysis using standard chemical methods to unfold the diverse classes of chemical constituents present and the identification of different constituents is based on the property of selective reactivity of phytochemicals present in an extract (WHO, 1998).

The major problem of quality assurance of herbal medicine has been solved to a great extent with the help of chromatographic print analysis and is considered as an effective method in discovering bioactive profile of plants of therapeutic importance. High performance thin layer chromatography (HPTLC) is an invaluable separation technique available today as an analytical

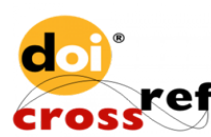


quality assessment tool for the rapid evaluation of botanical materials. HPTLC fingerprint profiles are preferred to identify the transparency and potency of herbal formulations due to its accuracy, precision and reproducibility along with its economical mobile phase consumption (Pattanaya et al., 2010). The present study is a first report on the phytochemical analysis of $F$. darshani and a simple, reproducible high performance thin layer chromatography was developed to evaluate the presence of berberine in the methanolic stem extracts of the plant.

\section{Materials and Methods}

Collection and identification of plant material

The stem cuttings of $F$. darshani were collected from Vellanipacha forests in Thrissur district. The plant samples were authenticated by taxonomist Dr. P. S. Udayan at Sree Krishna College, Guruvayur, Kerala. Voucher specimens were maintained for further reference.

\section{Preparation of plant extracts}

Matured stem cuttings of plants were thoroughly washed in running tap water and then rinsed in distilled water to remove the adherent soil. The stem was then cut into small pieces of $1-1.5 \mathrm{~cm}$ and shade dried for 5-6 days and powdered into fine powder. $20 \mathrm{gm}$ of the powdered stem sample of $F$. darshani was taken separately in clean conical flasks and extracted with $200 \mathrm{ml}$ of methanol by placing it in a magnetic stirrer for 12 hours. The extract obtained was filtered through Whatmann filter paper 1 and the process was repeated for three days till exhaustion. The fraction was evaporated to dryness and a semisolid sticky extract was obtained which was stored at $4^{\circ} \mathrm{C}$ in air-tight bottle for further use.

\section{Chemical and reagents}

All the chemicals, were of analytical grade from Merck Pvt. Ltd., Mumbai. Berberine was obtained from Sigma Aldrich, India. The HPTLC was performed on $20 \mathrm{~cm} \times 20 \mathrm{~cm}$ plates of silica gel $60 \mathrm{~F}_{254}$ (Merck KGaA, Darmstadt, Germany).

\section{Preliminary phytochemical screening}

The preliminary phytochemical analysis was performed on the methanolic extract of the stem samples following the standard procedures as described by Harborne to identify the active constituents (1973).

\section{Tests for carbohydrates}

Molisch's Test: To $2 \mathrm{ml}$ of extract 2-3 drops of alpha naphthalene solution in alcohol was added, shaken for $2 \mathrm{~min}$ and $1 \mathrm{ml}$ of concentrated sulphuric acid was added slowly from the sides of the test tube. A deep violet colour at the junction of two layers indicates the presence of carbohydrates.
Test for reducing sugars

Fehling's Test: Filtrates were hydrolysed with dil. hydrochloric acid, neutralized with alkali and heated with $1 \mathrm{ml}$ each of Fehling's A \& B solutions. Formation of red precipitate indicates the presence of reducing sugars.

Benedict's test: Filtrates $(2 \mathrm{ml})$ were treated with Benedict's reagent in attest tube and heated gently in boiling water bath for $10 \mathrm{~min}$. Changes in colour to yellow, green and orange red precipitate indicates the presence of reducing sugars.

\section{Tests for glycosides}

Legal's Test: $2 \mathrm{ml}$ of extract was treated with $1 \mathrm{ml}$ sodium nitropruside in pyridine $(1 \mathrm{ml})$ and sodium hydroxide. Formation of pink to blood red colour indicates the presence of cardiac glycosides.

Keller-Killiani test: To the test tubes containing 2 $\mathrm{ml}$ of extract, $1 \mathrm{ml}$ of glacial acetic acid, 3 drops 5\% $\mathrm{W} / \mathrm{V}$ ferric chloride and concentrated sulphuric acid were added and observed. Appearance of reddish brown ring at the junction of the liquids indicates the presence of cardiac glycosides.

\section{Test for Alkaloids}

Mayer's Test: To $3 \mathrm{ml}$ of the extract, $1 \mathrm{ml}$ of Mayer's reagent (potassium mercuric iodide) was added. The appearance of white precipitate indicates the presence of alkaloids.

Wagner's Test: To $3 \mathrm{ml}$ of filtrate, $1 \mathrm{ml}$ of Wagner's reagent (iodine in potassium iodide) was added. The appearance of reddish brown precipitate indicates the presence of alkaloids.

Dragendorff's Reagent: To $2 \mathrm{mg}$ of the methanolic extract $5 \mathrm{ml}$ of distilled water was added, 2M Hydrochloric acid was added until an acid reaction occurs. To this $1 \mathrm{ml}$ of Dragendorff's reagent was added. Formation of orange or orange red precipitate indicates the presence of alkaloids.

\section{Test for Saponins}

Foam Test: The extract (2g) was shaken vigorously with $20 \mathrm{ml}$ of water and observed for persistent foam, which indicates the presence of saponins.

\section{Test for flavonoids}

Shinoda Test: To a small quantity of test residue, 5 $\mathrm{ml}$ of ethanol $(95 \% \mathrm{v} / \mathrm{v}), 5$ drops of hydrochloric acid and $0.5 \mathrm{~g}$ of magnesium turnings were added. Appearance of pink, crimson or magenta colour indicates the presence of flavonoids.

\section{Test for Triterpenoids and Sterols}

Liebermann Burchard Test: To the chloroform solution of the extract, 3-4 drops of acetic anhydride was added and mixed well. To this $5 \mathrm{ml}$ of concentrated sulphuric acid was added from the sides of the test tube. A brown reddish ring appears at the junction of two layers. The upper layer showing greenish blue colour indicates the presence of triterpenoids or sterols. 
Salkowaski's Test: To the chloroform solution of the extract, few drops of concentrated sulphuric acid was added, shaken and allowed to stand. Appearance of reddish brown colour of the interface indicates the presence of triterpenoids or sterols.

\section{Test for Anthraquinones}

Borntrager's Test: Borntrager's test is employed for presences of anthraquinones. The extract is boiled with dilute sulphuric acid, filtered and to the filtrate benzene, or ether or chloroform is added and shaken well. The organic layer is separated to which ammonia is added slowly. The ammoniacal layer shows pink to red color due to presences of anthraquinone glycosides.

\section{Test for Tannins and Phenols}

Ferric chloride Test: To $3 \mathrm{ml}$ of extract, $3 \mathrm{ml}$ of $5 \% \mathrm{w} / \mathrm{v}$ ferric chloride solution was added. A dark green or deep blue colour indicates the presence of tannins and phenols.

\section{High Performance Thin layer Chromatography (HPTLC)}

\section{Preparation of standard and sample solution}

The standard solution was prepared containing known concentration by dissolving $1 \mathrm{mg}$ standard of berberine in $10 \mathrm{ml}$ of chromatographic grade methanol $(0.1 \mathrm{mg} / \mathrm{ml})$. Concentrated plant extracts were filtered and stock solution containing $10 \mathrm{mg}$ of plant extract in $10 \mathrm{ml}$ methanol was prepared (1.0 $\mathrm{mg} / \mathrm{ml})$.

\section{Development of the optimum mobile phase}

The mobile phase composition for development of chromatographic method was optimized by testing different solvent mixtures of varying polarity in different ratios. The satisfactory resolution was obtained with the solvent system consisting of Chloroform: Ethyl acetate: Methanol: Formic acid 4:5:4:0.3 (v/v/v/v).

\section{Chromatographic conditions}

Chromatography was performed on precoated silica gel Merck $60 \mathrm{~F}_{254}$ HPTLC plates of $0.2 \mathrm{~mm}$ thickness $(20 \mathrm{x} 20 \mathrm{~cm}) .10 \mu \mathrm{l}$ of methanolic extracts of plant samples and standard compound berberine were applied to the plate positioned at $10 \mathrm{~mm}$ from the bottom using a CAMAG automated TLC applicator (automated spray-on applicator equipped with a $100 \mu$ l syringe operated with a band width $8 \mathrm{~mm}$, distance between band $15 \mathrm{~mm}$ and distance from the side edge of plate $15 \mathrm{~mm}$ ). Plate was eluted in pre- saturated twin trough chamber (CAMAG $\left.\mathrm{ADC}_{2}\right)$ in ascending mode at room temperature $(25$ $\pm 2{ }^{\circ} \mathrm{C}$ ) with the mobile phase Chloroform: Ethyl acetate: Methanol: Formic acid (4:5:4:0.3). The length of the chromatogram run was $80 \mathrm{~mm}$. After complete development, the TLC plates were dried on CAMAG TLC plate heater III at $105^{\circ} \mathrm{C}$ for 5 minutes. After drying the spots were visualized under CAMAG UV cabinet 254 and $366 \mathrm{~nm}$. Then the plates were scanned in the densitometer by linear scanning using CAMAG TLC scanner III equipped with WINCATS software (CAMAG). The identification of berberine in the methanolic extracts of stem of the plants was confirmed by superimposing the UV spectra of samples and standards within the same retardation factor $\left(R_{\mathrm{f}}\right)$ value.

\section{Results and Discussions}

The present study is a first report on the phytochemical analysis of the endemic plant $F$. darshani. The preliminary phytochemical screening carried out with the methanolic extract of stem provides evidence that the plant is a potent source of secondary metabolites like alkaloids, terpenoids, sterols, carbohydrates, reducing sugars, anthraquinones, phenols, tannins, terpenoids, sterols and flavonoids which are medicinally important bioactive compounds that can be used for novel drug discovery in the pharmaceutical sector for the treatment of various diseases. Glycosides and saponins were found to be absent in methanol extracts from stem of F. darshani (Table $1)$.

HPTLC fingerprint profiles are important parameters of herbal drug standardization for the proper identification of medicinal plants. Different mobile phase compositions were employed to achieve good separation for optimization of method. The solvent system containing Chloroform: Ethyl acetate: Methanol: Formic acid $(4: 5: 4: 0.3)(\mathrm{v} / \mathrm{v} / \mathrm{v} / \mathrm{v})$ resulted in good resolution of berberine in the presence of other compounds in plant extract of F.darshani (Fig. 1). The $\mathrm{R}_{\mathrm{f}}$ value (0.97) for berberine in reference standard and plant sample of F.darshani was found comparable under UV light at $366 \mathrm{~nm}$ (Fig. 2\&3). A number of protoberberine alkaloids and an aporphine alkaloid, magnoflorine, were isolated and characterized in previous phytochemical studies of F. tinctoria (Siwon et al.,1981).Three protoberberine alkaloids, berberine chloride, berberrubine chloride and thalifendine chloride has been reported to be isolated from the roots of F. tinctoria Lour. and was found to show significant cytotoxic activity with one or more human cancer cell-lines (Jin Rui et al., 1993). The compounds palmatine, berberine, jatrorrhizine, palmatrubine, 7, 8-dihydro-8hydroxyberberine and groenlandicine has been reported from related species F. recisa Pierre. (He et al., 2009).

This standardisation method will provide rapid, cost effective and specific method to develop and identify the biomarker berberine in F. darshani and assist in the characterisation, selection, multiplication and conservation of genetically 
superior planting material of assured uniformity and desired quality.

Table 1. Phytochemical screening in methanolic extracts of stem of Fibraurea darshani.

\begin{tabular}{lc}
\hline Phytochemical tests & Fibraurea darshani \\
\hline Test for Carbohydrates & + \\
Molisch's test & \\
Test for Reducing Sugar & + \\
Fehling's test & + \\
Benedict's test & \\
Test for Glycosides & - \\
Keller-Killani test & + \\
Test for Anthraquinones & \\
Benzene+ammonia & ++ \\
Test for Alkaloids & ++ \\
Mayer's reagent & ++ \\
Wagner's test & \\
Baeyer's test & - \\
Test for Saponins & + \\
Froth formation test & + \\
Test for Sterols and Terpenoids & + \\
Liebermann Burchard test & \\
Salkowski's test & - \\
Test for Tannins & + \\
and Phenolics & \\
Ferric chloride test & ++ \\
Iodine test & \\
Test for Flavonoids & \\
Alkaline reagent test & \\
\hline+ Prominently present, + Moderately present, & Absent
\end{tabular}

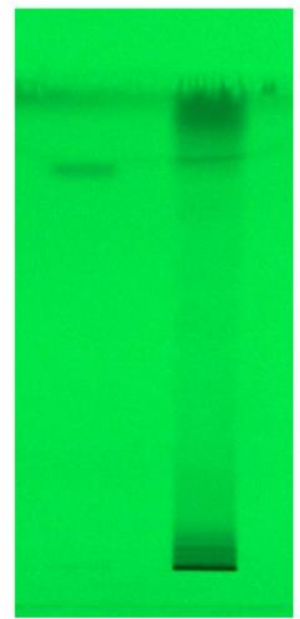

A

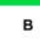

$254 \mathrm{~nm}$

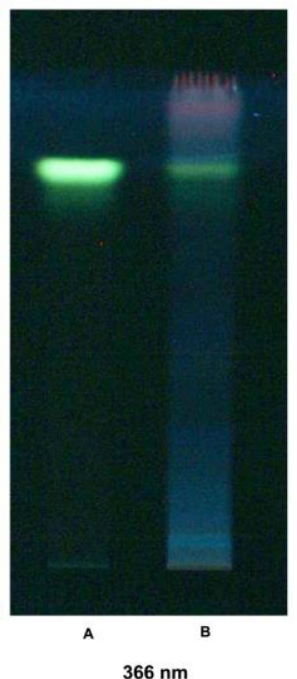

Figure 1. HPTLC profile of standard Berberine (A) and Fibraurea darshani (B) at 254 and 366nm Trask 1.10: BERgER EIN STD

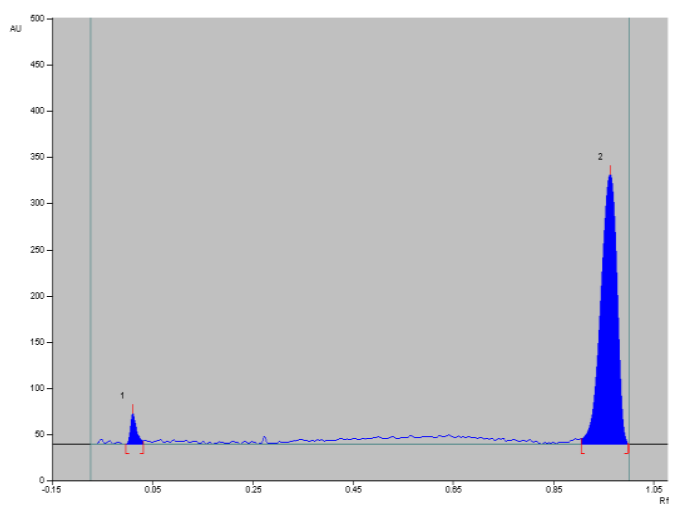

Figure 2. Chromatogram of Berberine at 366nm

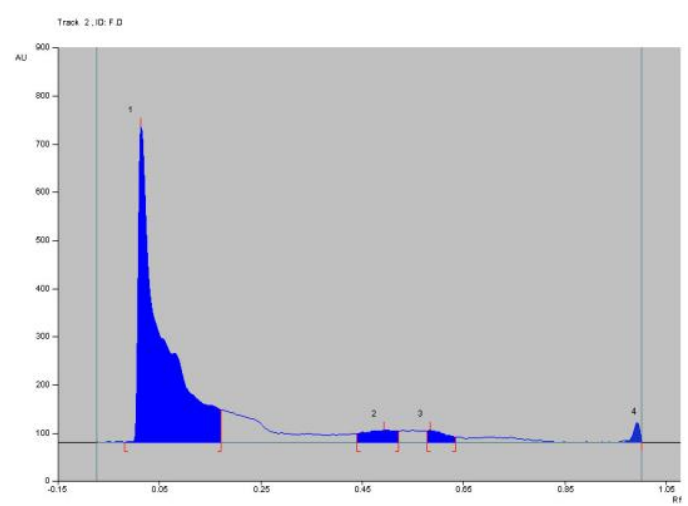

Figure 3. Chromatogram of methanolic extract of stem of Fibraurea darshani at $366 \mathrm{~nm}$

\section{Conclusion}

Various forms of traditional, complementary and alternative medicines are playing progressively more important role in health care globally. Therefore their safety, efficacy, and quality control are important concerns today. In India, medicinal plants are used for various therapeutic purposes in Ayurvedic and folk medicines. Over the years, due to the increased demand and over-exploitation, the much needed medicinal plants have become rare or even depleted from their natural habitats. Moreover, the botanical source of a raw drug is often attributed to one species in most of the Indian systems of medicines. The continuous extraction of a particular species will lead to its depletion as well as the loss of biodiversity of their habitats. Also the herbal industry is facing a major threat in the production of commercial natural products due to adulteration and substitution of medicinal plants. To an extent the use of related species with accurate scientific evaluation can overcome this problem. Hence, the identification of plants and its chemical constituents in the phytochemical industry is an important criteria.

\section{Acknowledgements}

The authors express gratitude to UGC, Government of India for the financial support as research grant. The authors are also thankful to Dr. G. Jayakrishnan, Head of the Department, Botany, Sree Krishna College, Guruvayur for his valuable suggestions and support.

\section{References}

1. Calixto BJ. Efficacy, safety, quality control, marketing and regulatory guidelines for herbal medicines (phytotherapeutic agents). Brazilian Journal of Medical and Biological Research 33(2000): 179-89.

2. Dar GH and Faroog S. How Diverse is Biodiversity! Do we know? Oriental Science. 2.1 (1997): 51-69.

3. Forman LL. A revision of tribe Fibraureae (Menispermaceae) in Asia. The Menispermaceae of 
Malaysia and adjacent areas XIII. Kew Bulletin 40 (1985): 539-551.

4. Harborne JB. Phytochemical Methods. Chapman and Hall Ltd, London (1973): 49-188.

5. He R, Ma HF, Yang W, Su ZL and Zhao YF. Study on the determination of akaloid in Fibraurea recisa Pierre with high performance liquid chromatography. Anbui Nong Ye Ke Xue 37 (2009): 9980-9981.

6. Jin Rui D, Heebyung C, John MPA, Douglas K, Soefjan $\mathrm{T}$ and Kosasih P. Cytotoxic constituents of the roots of the Indonesian medicinal plant Fibraurea cbloroleuca. Phytotherapy Research 7 (1993): 290-294.

7. Keawpradub N, Dej-adisai, S and Yuenyongsawad S. Antioxidant and cytotoxic activities of Thai medicinal plants named Khaminkhruea: Arcangelisia flava, Coscinium blumeanum and Fibraurea tinctoria. Songklanakarin Journal of Science and Technology 27 (2005): 455-467.

8. Kubitzki K, Rohwer JG, and Bittrich V. The families and genera of vascular plants, Vol. II. SpringerVerlag, Berlin Heidelberg, Germany (1993).

9. Mabberle DJ. Mabberley's plant-book: A portable dictionary of the vascular plants, their classification and uses. 3rd edition. Cambridge University Press (2008).
10. Patani A, Indian Herbal Pharmacopoeia. Revised New ed. Indian Drug Manufacturers Association, Mumbai (2002).

11. Perry LM and Metzger J, Medicinal plants of East and Southeast Asia Attributed Properties and Uses,Vol. 620, MIT Press, Cambridge, London (1980).

12. Pramanik A and Gangopadhyay M. Flora of India, Vol.1. Botanical Survey of India, Calcutta (1993).

13. Rao GX, Zhang S, Wang HM, Li ZM, Gao S, Xu GL. Antifungal alkaloids from the fresh rattan stem of Fibraurea recisa Pierre. Journal of Ethnopharmacology 123.1 (2009):1-5.

14. Siwon J, Verpoorte R and Baerheim SA. Studies on Indonesian medicinal plants. VI. Further alkaloids from Fibraurea chloroleuca. Planta Medica 41 (1981): 6568.

15. Udayan PS, Ravikumar K, Ved DK and Udaiyan K, Fibraurea darshani, A new species of Menispermaceae from the Western Ghats, India. Rheedea 17 (2007): 912

\section{Cite this article as:}

Sheema Dharmapal P., Bindu T. K, P. S. Udayan and K. K. Elyas. HPTLC analysis of berberine in stem extracts of Fibraurea darshani. Annals of Plant Sciences 7.2 (2018) pp. 2021-2025.

do $\mathrm{http://dx.doi.org/10.21746/aps.2018.7.2.7}$

Source of support: UGC, Government of India.

Conflict of interest: Nil 